
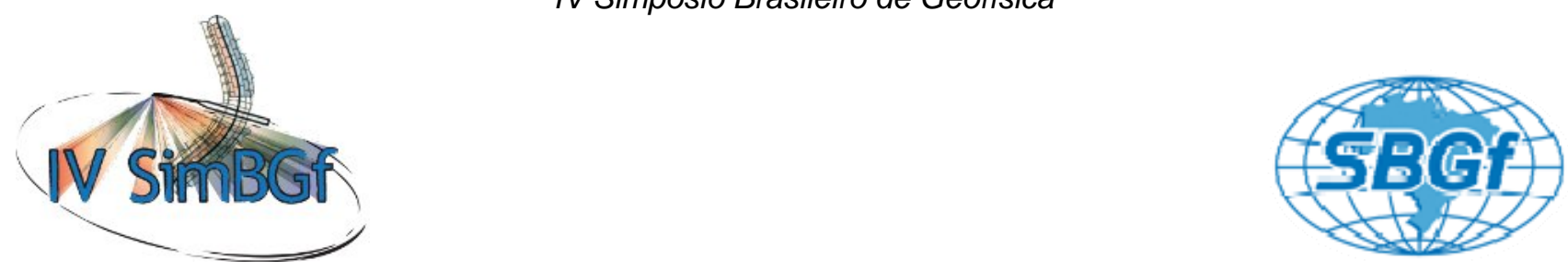

\title{
Utilização de Dados de GPR e de Sondagens na Reconstrução Paleoambiental da Planície Costeira de Itaipuaçú, Município de Maricá (RJ), Durante o Quaternário.
} Alipio José Pereira, PETROBRAS S.A. - Brasil; Luiz Antonio Pierantoni Gamboa, PETROBRAS S.A. - Brasil; Maria Augusta
Martins da Silva - Universidade Federal Fluminense (UFF); Amilsom Rangel Rodrigues, PETROBRAS S.A. - Brasil.

Copyright 2010, SBGf - Sociedade Brasileira de Geofísica

Este texto foi preparado para a apresentação no IV Simpósio Brasileiro de Geofísica, Brasília, 14 a 17 de novembro de 2010. Seu conteúdo foi revisado pelo Comitê Técnico do IV SimBGf, mas não necessariamente representa a opinião da SBGf ou de seus associados. É proibida a reprodução total ou parcial deste material para propósitos comerciais sem prévia autorização da SBGf.

\section{Abstract}

The integration of ground penetrating radar (GPR) data with data of soundings had disclosed important considerations on the evolution of the coastal plain of Itaipuaçú, city of Maricá, State of Rio de Janeiro, during the Quaternary. The paleomorphology of the basement seen in subsurface (GPR images) and in some points located in the plain (outcrops) show that the basement strong controlled the overlapped deposits, and that they correspond to the Coastal Sequence Sedimentary of Itaipuaçú. This sedimentary package reflects the variations of the sea level occured in the last thousands of years in the region, being represented by five intervals that correspond to the positions that the shoreline tried throughout the time (regressions and transgressions) and have aggradated the coastal plain until today.

\section{Introdução}

A área de estudos possui $10 \mathrm{~km}$ de arco praial e está situada na planície costeira de Itaipuaçú, município de Maricá, Estado do Rio de Janeiro, entre a Pedra do Elefante (Serra da Tiririca) e a região conhecida como Pontal de Itaipuaçú (figura 1). A motivação para a realização do estudo foi de estudar o arcabouço sedimentar estratigráfico da planície costeira de Itaipuaçú, e entender como ocorreu o preenchimento da planície costeira durante os últimos milhares de anos, em função das variações do nível do mar ocorridas no Quaternário.

Ao estudar a estratigrafia das regiões costeiras, buscamos no tempo e no espaço reconstruir eventos referentes aos avanços e recuos das linhas de costa, devido principalmente as variações do nível do mar, uma vez que os registros desses eventos podem ser preservados nos pacotes sedimentares (Pereira et al., 2001).

O levantamento com GPR totalizou $47 \mathrm{~km}$ de linhas paralelas e perpendiculares a praia, e as sondagens a percussão foram realizadas em 13 pontos da planície costeira. A interação das duas ferramentas permitiu identificar o contato entre o embasamento alterado e o pacote sedimentar, que ocorre de forma bastante irregular, com grande variação em profundidade ao longo de toda a planície. Foram também identificados 5 intervalos com características regressivas/transgressivas que representam a dinâmica ocorrida durante o Quaternário na região.

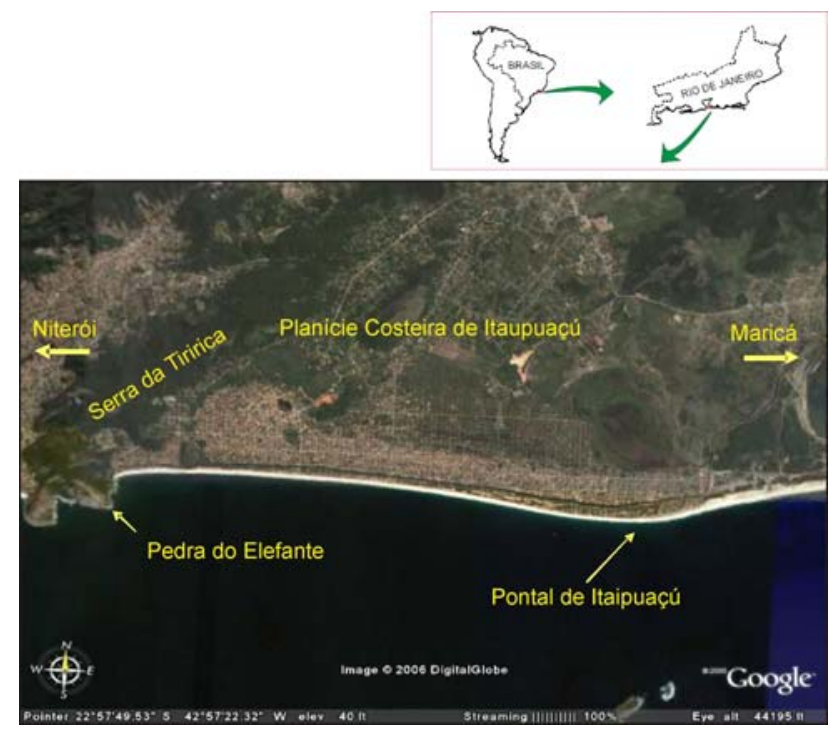

Figura 1 - Mapa de localização da área de estudo.

\section{Métodos}

A escolha de dois tipos de antenas de GPR teve como objetivo o imageamento de feições profundas (antenas de $80 \mathrm{MHz}$ ) e do reconhecimento de estruturas rasas (antenas de $200 \mathrm{MHz}$ ). A malha de aquisição obedeceu a seguinte geometria: 11 linhas perpendiculares à praia e 3 linhas paralelas à praia, cobrindo os $10 \mathrm{Km}$ de arco praial (figura 2). Foram realizadas 13 sondagens à percussão ao longo da planície costeira, num total de $366 \mathrm{~m}$ lineares de material sondado, com profundidades máximas alcançando entre 15 m (mínimo) e 48,30 m (máximo) nos poços. Do material recolhido nas sondagens, na maior parte friável (material arenoso), foi feita análise granulométrica a cada metro, enquanto que do material com características coesivas, foram recuperados testemunhos para confecção de lâminas petrográficas num total de $19 \mathrm{~m}$ lineares amostrados.

\section{Resultados}

Embora a planície costeira de Itaipuaçú esteja em franca expansão urbana, com inúmeras construções sendo 
edificadas e alteração do meio físico, as imagens obtidas através dos dois levantamentos com GPR mostraram a eficiência da ferramenta geofísica em trabalhos dessa natureza. A campanha com antenas de $200 \mathrm{MHz}$ alcançou em torno de 12 a $15 \mathrm{~m}$ de profundidade e, entre 30 e $32 \mathrm{~m}$, com antenas de $80 \mathrm{Mhz}$. Dessas imagens foi possível identificar padrões de reflexão que representam a resposta do sinal do georadar em função das características do subestrato. A associação desses padrões de reflexão permite visualizar elementos arquitetônicos diagnósticos de ambientes costeiros. Foram identificados nas imagens dos perfis, escarpas de tempestades, paleocanais, leques de sobrelavagem, paleolagunas, sequencias de refletores indicando mudanças no padrão deposicional (superfícies discordantes) e refletores que representam a migração dos paleocordões. O embasamento que serviu de base para o pacote sedimentar costeiro ocorre de três formas ao longo da área de estudo: superficialmente e em forma de arco, a oeste da praia, entre Pedra do Elefante e a Serra da Tiririca; horizontalizada e com mergulho suave na direção do mar, entre o Morro da Peça até o centro da praia e, de forma irregular (altos e baixios), do centro da praia até a APA de Itaipuaçú. A intensa migração lateral observada em um dos perfis paralelos a praia (refletores progradando), próximo da região do Pontal de Itaipuaçú, indica que o transporte litorâneo de leste para oeste foi o responsável pela construção da praia ao longo do tempo, preenchendo uma reentrância (baia) localizada entre o alto do embasamento na região do Pontal de Itaipuaçú identificado nos perfil de GPR, e o Pontal de Ponta Negra, hoje região onde se encontra uma sequencia de lagoas (lagoa de Maricá, da Barra e Guarapina) (figura 3). As correntes marinhas de leste para oeste e as variações do nível do mar durante os últimos milhares de anos foram responsáveis pela dinâmica de colmatação e edificação da praia.

Das análises realizadas a partir das amostras dos sedimentos inconsolidados e dos testemunhos recuperados nos 13 poços, através das sondagens a percussão, foi possível identificar intervalos que constituem a Sequencia Costeira de Itaipuaçú formada por três unidades litoestratigráficas: unidade $A$, constituída exclusivamente por material dos vários níveis de alteração do embasamento; unidade B, formada por uma mistura de material dos níveis de alteração do embasamento e material arenoso/lamoso, com características de barreira/restinga; unidade $\mathrm{C}$, com apenas depósitos característicos de barreira/restinga (figura 4). Na unidade C (Sequencia Sedimentar Costeira de Itaipuaçú) foram reconhecidos 5 estágios que representam a história deposicional dessa parte do litoral fluminense (Pereira, 2009), sendo assim constituída: O primeiro estágio (regressivo) está representado pela exposição total do material oriundo do embasamento. $\mathrm{O}$ segundo estágio (transgressivo/regressivo 1) indica uma subida constante do nível do mar, mas com dois momentos intermediários que formaram em tempos diferentes dois sistemas de barreira-laguna. O terceiro estágio (transgressivo/regressivo 2) representa uma mudança na paleolinha de costa, indicando que o sistema passa de retrogradacional para progradacional.
No quarto estágio, transgressivo/regressivo 3, observamse dois tempos com pequenas subidas e descidas do nível do mar, formando dois sistemas barreira-laguna. $\mathrm{O}$ último estágio está representado por uma tendência de subida do nível do mar percebida até os dias de hoje na área de estudo (figura 5).

\section{Conclusão}

A utilização de duas ferramentas geofísicas, GPR e sondagens, demonstrou ser uma excelente combinação na aquisição de dados e no estudo da estratigrafia da região costeira de Itaipuaçú. Com o conhecimento das características dos sedimentos obtidos através das análises dos seus constituintes (amostras de calha e testemunhos) e do imageamento com GPR dos corpos, além da sua distribuição pela planície costeira, foi possível ter uma visão tridimensional do arcabouço estrutural e sedimentar local, bem como do controle dos intervalos estratigráficos. Outro fator importante verificado a partir da metodologia utilizada no trabalho é a possibilidade de utilizar várias escalas de observação. Não só as informações obtidas pelo mapeamento regional por parte do GPR (macroescala), em escala de afloramento (mesoescala) através de testemunhos e amostras de calha, mas também, uma terceira escala de observação foi realizada com a confecção de lâminas delgadas, possibilitando observar aspectos petrográficos (microescala) que normalmente não são vistos em estudos dessa natureza.

\section{Agradecimentos}

Agradecemos as gerencias de Sedimentologia e Petrografia do Cenpes-Petrobras (GSEP), pela utilização dos seus laboratórios e apoio na realização das sondagens, e a Gerencia de Geofísica do Cenpes Petrobras, pela cessão do GPR.

\section{Referencias}

Pereira A.J., 2009. Caracterização Estratigráfica da Planície Costeira de Itaipuaçú (Maricá) - Rio de Janeiro, Durante o Quaternário. Tese de Doutorado. Programa de de Pós-Graduação em Geologia e Geofísica Marinha da Universidade Federal Fluminense (UFF), 388 p.

Pereira A.J., Gamboa L.A.P., Silva M.A.M. da, Costa A. da, Rodrigues, A.R., 2001 - Utilização do GPR na Investigação da Estratigrafia da Região Costeira de Itaipuaçú - Maricá (RJ). Anais do Sétimo Congresso Internacional da Sociedade Brasileira de Geofísica. TS20: 352-355, Salvador, Bahia. 
Utilização de Dados de GPR e de Sondagens na Reconstrução Paleoambiental da Planície Costeira de Itaipuaçú, Municípiœ de Maricá (RJ), Durante o Quaternário.

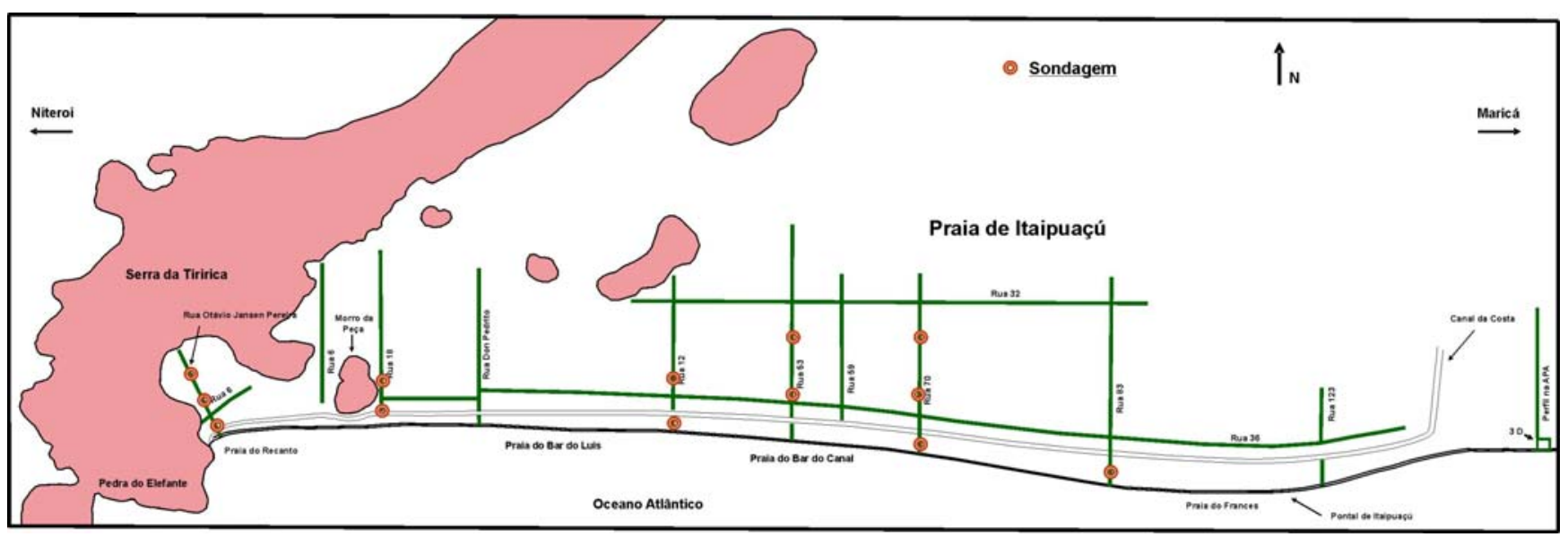

Figura 2. Desenho esquemático mostrando a região onde foi feita a aquisição com GPR e a posição das 13 sondagens a percussão. As linhas verdes indicam o encaminhamento dos perfis (11 linhas perpendiculares a praia e 3 linhas paralelas a praia) e os pontos vermelhos as posições das sondagens.

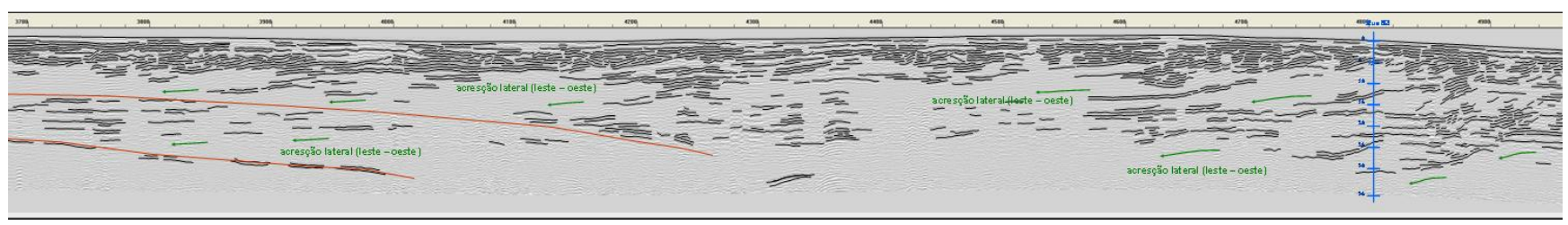

Figura 3 - Perfil de GPR interpretado indicando a forte migração de leste para oeste responsável pela edificação de parte da praia de Itaipuaçú, na região do Pontal de itaipuaçú..

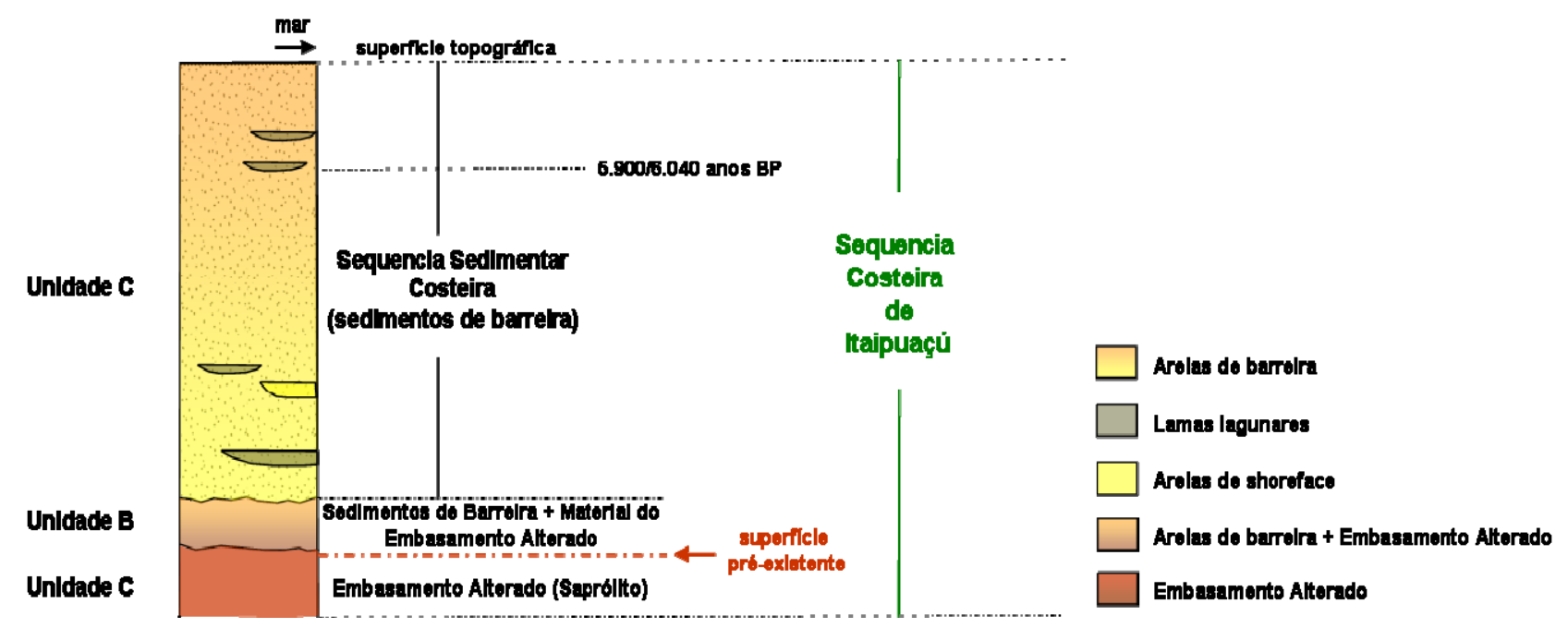

Figura 4 - Desenho esquemático com a coluna litoestratigráfica representando a Sequencia Costeira de Itaipuaçú, com as unidades, litofácies e principais superfícies discordantes. 


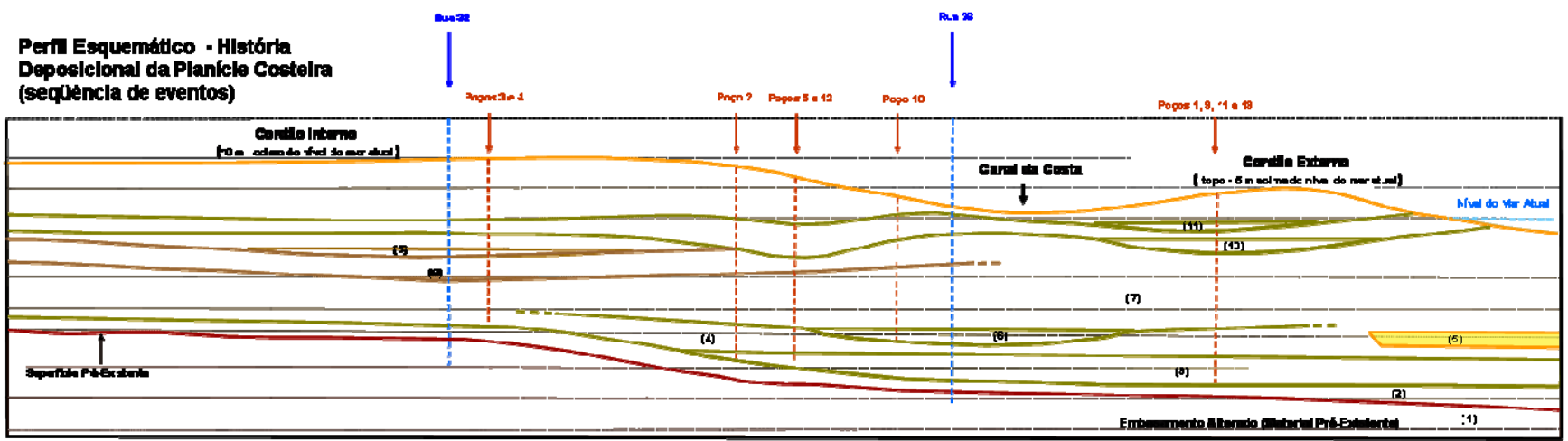

Legenda com a Descrição dos Principais Eventos e Feições Identificadas no Trabalho - História Deposicional da Planície Costeira de Itaipuaçú

(1) ra:oial pró oxistente const tuíde po- matorial provo ionto do ombajomonto alterado (nívcis co alteraçăo) que reoresen:a a fácies embasamento alterado

(2) ristura do material pré-existente com are as de berreira/restinge onde predominam as fraçöes areia grossa/mu ito grossa que represerta as fácies areia lamcsà ?a fácies areia

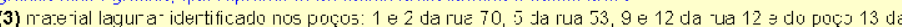

rua 83 que repeserta a fácies argila arenosa/lama arenoŁa.

(4) areias de barreira/resting $\varepsilon$ constituidas principalmente pelas fraçóes areia grossaimuito grossa, que

6) arelas de storeface constituidas pelac fraçöes areia muito fina/fina que representam a fác es areia.

(6) rra:o ial lagur a- idertificado no foşo 10 ca rua 18 que roprosenta a fácios acçila aronosa/lama aronosa

(7) areias de barreira/restıng $\varepsilon$ constituidas pnncipalmente pelas traçöes arela grossa'multo grossa э

representam a 'asies areia.

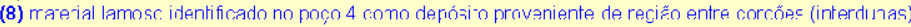

erepresentam a fácies argila arencosallama arenusa.

(9) ra:ejal lamosr identificado no poço 4 conn depósion proveniente de reçižno entre corconec (interdunas)

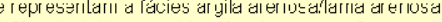

(10) material lagı nar idenif cado ro poço 9 ca rua 12 representado pela fácies arçila arənosa/lama

arenosa e correlac oาado com os depísitos lagunarəs do foşo realizaco no cordáo externo da APA de

Itaipuaçú c.jia dataçăo da matéria orgåniza aprassntol a idado do $5.900 / 6040$ anos BF.

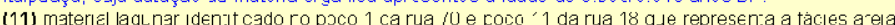

larrosa preta.

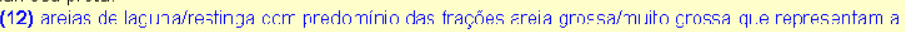

áce es areia

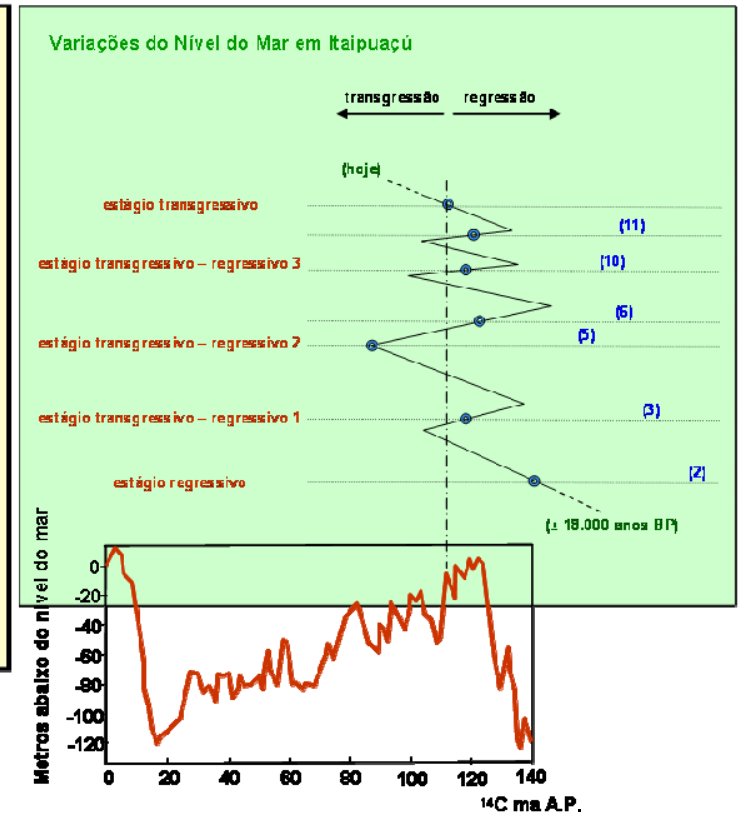

Figura 5 - Perfil esquemático representando toda seqüência dos eventos identificados nas imagens de GPR e nas sondagens, e que representam a historia deposicional da planície costeira de Itaipuaçú nos últimos milhares de anos. 